\title{
Effect of Hydroxyethyl Starch 130/0.4 on Blood Loss and Coagulation in Patients With Recent Exposure to Dual Antiplatelet Therapy Undergoing Off-Pump Coronary Artery Bypass Graft Surgery
}

\author{
Jeong Soo Lee, MD; So Woon Ahn, MD; Jong Wook Song, MD; \\ Jae Kwang Shim, MD, PhD; Kyung-Jong Yoo, MD, PhD; Young Lan Kwak, MD, PhD
}

\begin{abstract}
Background: Hydroxyethyl starch (HES) solutions are often used for maintaining intravascular volume and improving microperfusion, while a large amount of HES can cause adverse effects on coagulation. As the indications for clopidogrel expand, an increasing number of patients undergoing off-pump coronary artery bypass surgery (OPCAB) are also undergoing dual antiplatelet therapy (DAPT), with its higher risk of bleeding complications. The aim of the present study was to determine whether a moderate dose of $6 \%$ HES 130/0.4 significantly increases perioperative blood loss in patients with continued DAPT within 5 days of OPCAB.
\end{abstract}

\begin{abstract}
Methods and Results: Patients who received clopidogrel and aspirin within 5 days of OPCAB were randomly allocated to receive HES 130/0.4 ( $\leq 30 \mathrm{ml} / \mathrm{kg}$ ) followed by crystalloid infusion (HES group, $n=53$ ), or crystalloid only (crystalloid group, $n=53$ ) perioperatively. The amount of perioperative blood loss (sum of bleeding during the intraoperative and postoperative 24-h period), transfusion requirements, modified thromboelastography and coagulation variables, hemodynamic parameters, and fluid balance were recorded. Perioperative blood loss and coagulation profiles were similar between the groups, but the postoperative hemoglobin level was higher in the crystalloid group.
\end{abstract}

Conclusions: Up to $30 \mathrm{ml} \cdot \mathrm{kg}^{-1}$. day ${ }^{-1}$ of $6 \%$ HES $130 / 0.4$ did not increase the perioperative blood loss compared to crystalloid in patients with recent exposure to DAPT undergoing OPCAB. HES 130/0.4 caused a similar degree and duration of coagulation impairment as observed when only crystalloid was given. (Circ $J$ 2011; 75: 2397-2402)

Key Words: Aspirin; Clopidogrel; Coagulation; 6\% Hydroxyethyl; Hydroxyethyl starch 130/0.4; Off-pump coronary artery bypass surgery

B ased on the clear ischemic benefits, dual antiplatelet therapy (DAPT) with aspirin and clopidogrel has become the cornerstone of the management of coronary artery disease..$^{1-3}$ Due to the potential risk of bleedingrelated complications, it was recommended that clopidogrel be discontinued at least 5 days prior to cardiac surgery with cardiopulmonary bypass (CPB) ${ }^{3-6}$ By avoiding $\mathrm{CPB}$, off-pump coronary artery bypass surgery (OPCAB) is associated with less deterioration in coagulation and has been suggested as an alternative surgical technique to CPB in patients exposed to recent antiplatelet therapy, mitigating perioperative blood loss while maximizing ischemic benefit. ${ }^{7-10}$
Colloids are often used in cardiac surgery because colloids are more efficient than crystalloids in maintaining intravascular volume and osmotic pressure, and improving microperfusion. ${ }^{11-16}$ Hydroxyethyl starch (HES) solutions, however, the most widely used synthetic colloids, cause adverse effects on coagulation that are mainly attributable to the mean molecular weight and degree of substitution. The recently developed HES 130/0.4 (Voluven ${ }^{\circledR}$; Fresenius Kabi, Bad Homburg, Germany) has a lower molecular weight and lower molar substitution ratios than its congeners, and has been reported not to increase postoperative blood loss significantly in patients undergoing cardiac surgery. ${ }^{17,18}$ When considering the use of HES 130/0.4

Received April 13, 2011; revised manuscript received May 26, 2011; accepted June 13, 2011; released online August 2, 2011 Time for primary review: 25 days

Department of Anesthesiology and Pain Medicine (J.S.L., J.W.S., J.K.S., Y.L.K.), Department of Thoracic and Cardiovascular Surgery (K.-J.Y.), Anesthesia and Pain Research Institute (J.K.S., Y.L.K.), Cardiovascular Research Institute (J.K.S., K.-J.Y., Y.L.K.), Severance Biomedical Science Institute (Y.L.K.), Yonsei University College of Medicine, Seoul; and Department of Anesthesiology and Pain Medicine, Kwangdong University College of Medicine, Goyang (S.W.A.), Republic of Korea

The first two authors contributed equally (J.S.L., S.W.A.).

Name of grant: No fund supported.

Mailing address: Young Lan Kwak, MD, PhD, Department of Anesthesiology and Pain Medicine and Anesthesia and Pain Research Institute, Yonsei University Health System, 250 Seongsanno, Seodaemun-gu, Seoul 120-752, Republic of Korea. E-mail: ylkwak@yuhs.ac

ISSN-1346-9843 doi:10.1253/circj.CJ-11-0404

All rights are reserved to the Japanese Circulation Society. For permissions, please e-mail: cj@j-circ.or.jp 
in patients with recent exposure to DAPT undergoing OPCAB, however, the additional risk of increased bleeding to inherent hemodilution by HES could affect perioperative blood loss and coagulation, even with a limited amount of HES, ${ }^{19}$ yet no comprehensive data exist.

The aim of the present study was therefore to investigate the effect of a moderate dose of $6 \%$ HES $130 / 0.4$ on perioperative blood loss and coagulation, including modified thromboelastography (TEG) parameters, in patients with continued DAPT within 5 days of $\mathrm{OPCAB}$ in a prospective and randomized trial.

\section{Methods}

With approval of the Institutional Review Board and informed consent from all patients, 106 patients scheduled for OPCAB who received clopidogrel and aspirin within 5 days of surgery were randomly allocated into the following 2 groups: HES 130/0.4 group $\left(\mathrm{n}=53\right.$, maximal dose, $\left.30 \mathrm{ml} \cdot \mathrm{kg}^{-1} \cdot \mathrm{day}^{-1}\right)$; and crystalloid group $(n=53)$. This was an open-label trial in which the endpoints were assessed blindly. The exclusion criteria included emergency surgery, myocardial infarction (MI), history of previous cardiac surgery, history of bleeding diathesis or hepatic dysfunction, left ventricular ejection fraction $<40 \%$, hemoglobin $<12 \mathrm{~g} / \mathrm{dl}$, platelet count $<100,000 \mathrm{~mm}^{3}$, abnormal prothrombin time (international normalization ratio [INR]) and activated partial thromboplastin time (aPTT), creatinine $>1.4 \mathrm{mg} / \mathrm{dl}$, and use of glycoprotein IIb/IIIa inhibitors.

Patients were managed perioperatively according to institutional standards by a single team of anesthesiologists and cardiothoracic surgeons. The standard monitoring devices included a pulmonary artery catheter (Swan-Ganz $\mathrm{CCOmbo}^{\circledR} \mathrm{CCO} / \mathrm{SvO}_{2}$; Edwards Lifesciences LLC, CA, USA), which was inserted via the right internal jugular vein under local anesthesia for continuous measurement of the cardiac index (CI), mixed venous oxygen saturation $\left(\mathrm{SvO}_{2}\right)$, right ventricular ejection fraction, and right ventricular end-diastolic volume index (RVEDVI).

The HES 130/0.4 or crystalloid (Plasma solution A; CJ, Seoul, Korea) was infused to maintain the $\mathrm{CI}>2.2 \mathrm{~L} \cdot \mathrm{min}^{-1} \cdot \mathrm{m}^{-2}$, $\mathrm{SvO}_{2}>60 \%$, and urinary output $>0.5 \mathrm{ml} \cdot \mathrm{kg}^{-1} \cdot \mathrm{h}^{-1}$. In the HES $130 / 0.4$ group, the maximal dose of HES $130 / 0.4$ was $30 \mathrm{ml}$. $\mathrm{kg}^{-1} \cdot \mathrm{day}^{-1}$, after which crystalloid, a balanced multiple electrolyte-containing isotonic solution, was infused. Norepinephrine or sodium nitroprusside was infused to maintain the mean arterial blood pressure (MAP) between 60 and $80 \mathrm{mmHg}$, and vasopressin ( 0.1 unit) was given when the norepinephrine requirement exceeded $>0.5 \mu \mathrm{g} \cdot \mathrm{kg}^{-1} \cdot \mathrm{min}^{-1}$. Vasopressin was infused (2-4 units/h) when the patient needed repeated boluses of vasopressin.

All surgical procedures were performed by 1 surgeon through a median sternotomy and the heart was displaced using a posterior pericardial stitch, large gauze swabs $(12 \times 70 \mathrm{~cm})$, and a tissue stabilizer (Octopus Tissue Stabilization System ${ }^{\circledR}$; Medtronic, Minneapolis, MN, USA). Systemic heparinization during anastomoses was achieved with $100 \mathrm{U} / \mathrm{kg}$ of porcine heparin with additional doses to reach the target activated clotting time (ACT; $>250 \mathrm{~s}$ ). On completion of the anastomoses, heparin activity was neutralized with protamine sulfate $(0.5 \mathrm{mg}$ / $150 \mathrm{U}$ of heparin). A cell salvage device was used during the surgery in all cases and salvaged blood was re-infused into the patient before the end of the surgery. None of the patients received aprotinin or anti-fibrinolytics through the study period. All patients were transferred to the intensive care unit (ICU) after surgery.

Allogeneic packed red blood cells (pRBCs) were transfused when the hemoglobin level was $<8 \mathrm{~g} / \mathrm{dl}$ throughout the study period. Fresh frozen plasma (FFP) was transfused when the postoperative INR was $>1.5$ with excessive bleeding $(>200 \mathrm{ml} / \mathrm{h})$ for 2 consecutive hours. The criteria for transfusion of platelets were a postoperative platelet count $<50,000 / \mathrm{mm}^{3}$ with excessive bleeding $(>200 \mathrm{ml} / \mathrm{h}$ ) for 2 consecutive hours. Surgical re-exploration was indicated when chest tube drainage was $>200 \mathrm{ml} / \mathrm{h}$ for 6 consecutive hours or $>400 \mathrm{ml}$ during the first hour postoperatively, despite a normal ACT and global coagulation status. Transfusions in the operating room and ICU were decided by the anesthesiologist and cardiothoracic surgeons, respectively, who were not involved in the current study.

Hemodynamic variables, including heart rate, MAP, CI, central venous pressure, mean pulmonary artery pressure, RVEDVI, and $\mathrm{SvO}_{2}$, were recorded after $15 \mathrm{~min}$ of induction of anesthesia (T1), during grafting of the obtuse marginal (OM) branch of the left circumflex coronary artery (T2), and after sternum closure (T3).

The hemoglobin level, prothrombin time INR, aPTT, and platelet count were recorded 1 day before and after surgery. Modified TEG was performed $15 \mathrm{~min}$ after the induction of anesthesia, $15 \mathrm{~min}$ after sternum closure, and $5 \mathrm{~h}$ after surgery.

The primary endpoint of the present study was to compare the difference in perioperative blood loss, which was the sum of blood loss during the intraoperative and postoperative 24-h period. Re-transfusion of blood using a cell salvage device was regarded as intraoperative bleeding. The blood that drained from the chest tube during $24 \mathrm{~h}$ in the ICU was regarded as postoperative blood loss. Total infused fluid volume, urine output, and transfusion requirements intraoperatively and $24 \mathrm{~h}$ postoperatively were also recorded.

The major morbidity endpoints were defined as permanent stroke, renal dysfunction, any cardiac surgery re-operation, prolonged ventilation $>48 \mathrm{~h}$, and deep sternal wound infections..$^{20,21}$ For clarification, renal dysfunction was defined as acute postoperative renal injury resulting in one or more of the following: increase in serum creatinine to $>2.0 \mathrm{mg} / \mathrm{dl} ; \geq 50 \%$ decrease in the estimated glomerular filtration rates compared to the baseline preoperative value; and a new requirement for dialysis. ${ }^{21,22}$ Postoperative MI was defined as the occurrence of an increase in troponin- $\mathrm{T} \geq 0.8 \mathrm{ng} / \mathrm{ml}$ and/or development of new pathologic $\mathrm{Q}$ wave on electrocardiogram. ${ }^{23}$ Troponin- $\mathrm{T}$ was evaluated 1 day prior to surgery and at 12,24 , and $48 \mathrm{~h}$ after surgery. The length of stay in the ICU and general ward was also recorded. All aforementioned parameters were assessed and recorded by the clinicians who were blinded the patient's group and who were not involved the study.

The sample size calculation was performed based on the data of a previous study; ${ }^{24}$ specifically, we considered a $150-\mathrm{ml}$ difference in perioperative blood loss to be statistically significant. Based on the results of OPCAB during 2008 in Yonsei University Hospital, ${ }^{25}$ the SD of perioperative blood loss was $250 \mathrm{ml}$. This calculation generated an estimate of 45 patients in each group with $80 \%$ power and an $\alpha$ level of 0.05 . Considering a $15 \%$ estimated dropout, we included 53 patients in each group. All data were expressed as the number of patients or mean \pm SD. Data were examined for a normal distribution of variance with ANOVA and expressed as the mean \pm SD. For an abnormal distribution of variance, data were assessed using a KruskalWallis test and measured median (interquartile range). Discrete variables between the groups were compared using a chi-square test or Fisher's exact test, and $\mathrm{P}<0.05$ was considered to be statistically significant. Statistical analyses were performed using SPSS 15.0 for Windows (SPSS, Chicago, IL, USA). 


\begin{tabular}{lccc|}
\hline Table 1. Demographic Data & & & \\
Age (years) & Crystalloid (N=53) & HES 130/0.4 (N=53) & P value \\
Gender (M/F) & $65 \pm 9$ & $63 \pm 8$ & 0.388 \\
BSA (m $\left.{ }^{2}\right)$ & $44 / 9$ & $43 / 10$ & 0.800 \\
LVEF (\%) & $1.77 \pm 0.16$ & $1.75 \pm 0.17$ & 0.658 \\
Preoperative medications & $61 \pm 10$ & $60 \pm 11$ & 0.621 \\
$\quad \beta$-blockers & & & \\
ACEI & $32(60)$ & $37(70)$ & 0.308 \\
CCB & $16(30)$ & $17(33)$ & 0.834 \\
Diabetes mellitus & $28(53)$ & $29(55)$ & 0.846 \\
Hypertension & $18(34)$ & $18(34)$ & 1.000 \\
No. grafts & $36(68)$ & $35(66)$ & 0.836 \\
Aspirin discontinued (days) & $3.6 \pm 0.9$ & $3.3 \pm 1.0$ & 0.121 \\
Clopidogrel discontinued (days) & $1.45 \pm 0.93$ & $1.79 \pm 0.92$ & 0.650 \\
Duration of surgery (min) & $1.66 \pm 1.02$ & $1.93 \pm 0.93$ & 0.370 \\
\hline
\end{tabular}

Data given as mean \pm SD or $n(\%)$.

HES, hydroxyethyl starch; BSA, body surface area; LVEF, preoperative left ventricular ejection fraction; ACEI, angiotensin-converting enzyme inhibitors; CCB, calcium channel blockers.

\begin{tabular}{|lccc|}
\hline \multicolumn{2}{|c|}{ Table 2. Fluid Balance and Transfusion During the Perioperative Period } & \\
& Crystalloid (N=53) & HES 130/0.4 (N=53) & P value \\
Perioperative blood loss ${ }^{\dagger}$ & $1,028 \pm 389$ & $978 \pm 347$ & 0.483 \\
OR & $218 \pm 161$ & $232 \pm 159$ & 0.637 \\
ICU24 & $810 \pm 322$ & $753 \pm 313$ & 0.353 \\
Transfused pRBC (units) & $1.6 \pm 1.2$ & $2.1 \pm 1.6$ & 0.316 \\
During operation & $0.7 \pm 0.8$ & $1.5 \pm 1.6$ & 0.115 \\
ICU24 & $0.9 \pm 1.0$ & $0.6 \pm 1.1$ & 0.508 \\
Transfused FFP (units) & $2.2 \pm 0.5$ & $2.6 \pm 1.2$ & 0.552 \\
During operation & $0.6 \pm 1.3$ & $0.4 \pm 0.9$ & 0.796 \\
ICU24 & $1.6 \pm 0.9$ & $2.1 \pm 1.4$ & 0.470 \\
Patients receiving pRBC ${ }^{\dagger}$ & $12(23)$ & $14(27)$ & 0.652 \\
Patients receiving FFP ${ }^{\dagger}$ & $5(9)$ & $8(15)$ & 0.379 \\
Crystalloid infused ${ }^{\dagger}$ & $8,342 \pm 1,794$ & $6,694 \pm 1,882$ & $<0.001$ \\
Colloid infused ${ }^{\dagger}$ & 0 & $1,458 \pm 465$ & $<0.001$ \\
Urine output ${ }^{\dagger}$ & $4,073 \pm 1,498$ & $3,772 \pm 921$ & 0.219 \\
\hline
\end{tabular}

Data given as mean \pm SD or $n(\%)$.

tIntraoperatively and during the first $24 \mathrm{~h}$ in the intensive care unit postoperatively.

ICU24, during the first $24 \mathrm{~h}$ in the intensive care unit postoperatively; pRBC, packed red blood cells; FFP, fresh frozen plasma.

\section{Results}

There were no significant differences in the demographic data, preoperative medications, number of grafts, and duration of surgery between the 2 groups (Table 1 ). No patients required emergency conversion to CPB due to intraoperative hemodynamic instability.

There was no significant difference in the amount of perioperative blood loss between the groups. The pRBC and FFP transfusion requirements, and the number of patients transfused were also not different between the groups. The total volume of fluids infused and urine output intraoperatively and $24 \mathrm{~h}$ postoperatively were similar between the groups (Table 2).

The changes in hemodynamic variables after $15 \mathrm{~min}$ of induction of anesthesia (T1), during grafting of the OM branch of the left circumflex coronary artery (T2), and after sternum closure (T3) were similar between the groups (Table 3).

The hemoglobin level was significantly higher in the crys- talloid group than in the HES 130/0.4 group postoperatively, although the hemoglobin levels were similar in the 2 groups preoperatively. The postoperative INR was significantly lower in the crystalloid group than the HES 130/0.4 group (1.09 \pm 0.07 and 1.12 \pm 0.09 in the crystalloid and HES 130/0.4 groups, respectively, $\mathrm{P}=0.028)$, while the INRs were similar in the 2 groups preoperatively $(0.98 \pm 0.76$ and $0.96 \pm 0.69$ in the crystalloid and HES 130/0.4 groups, respectively, $\mathrm{P}=0.237$ ). The remaining hematologic parameters were similar between the groups before and after the operation (Table 4).

Based on TEG analysis, there were no significant differences between the groups. Both groups demonstrated significant changes in $\mathrm{r}, \mathrm{k}$, maximum amplitude (MA), and the $\alpha$-angle at T2 compared to the corresponding baseline values at $\mathrm{T} 1$, which returned to baseline at T3 (Table 5).

The number of patients requiring vasopressors was not different between the groups ( $n=44$ and $n=43$ in the crystalloid and HES 130/0.4 groups, respectively, $\mathrm{P}>0.999$ ), and the mean dose 


\begin{tabular}{|c|c|c|c|}
\hline Group & T1 & T2 & T3 \\
\hline \multicolumn{4}{|c|}{ Heart rate (beats/min) } \\
\hline Crystalloid & $61 \pm 10$ & $65 \pm 10$ & $66 \pm 9$ \\
\hline HES 130/0.4 & $61 \pm 11$ & $67 \pm 10$ & $68 \pm 9^{*}$ \\
\hline \multicolumn{4}{|l|}{ MAP (mmHg) } \\
\hline Crystalloid & $72 \pm 8$ & $73 \pm 8$ & $73 \pm 12$ \\
\hline HES 130/0.4 & $71 \pm 9$ & $72 \pm 7$ & $73 \pm 10$ \\
\hline \multicolumn{4}{|l|}{$\mathrm{Cl}\left(\mathrm{L} \cdot \mathrm{min}^{-1} \cdot \mathrm{m}^{-2}\right)$} \\
\hline Crystalloid & $2.6 \pm 0.5$ & $1.9 \pm 0.4$ & $2.4 \pm 0.5$ \\
\hline HES 130/0.4 & $2.6 \pm 0.7$ & $2.0 \pm 0.5$ & $2.5 \pm 0.5$ \\
\hline \multicolumn{4}{|l|}{ CVP (mmHg) } \\
\hline Crystalloid & $8 \pm 2$ & $10 \pm 3$ & $9 \pm 2$ \\
\hline HES 130/0.4 & $8 \pm 2$ & $10 \pm 2$ & $8 \pm 2$ \\
\hline \multicolumn{4}{|l|}{ MPAP $(\mathrm{mmHg})$} \\
\hline Crystalloid & $13 \pm 3$ & $14 \pm 3$ & $13 \pm 3$ \\
\hline HES 130/0.4 & $12 \pm 4$ & $14 \pm 4$ & $12 \pm 3$ \\
\hline \multicolumn{4}{|l|}{ RVEDVI $\left(\mathrm{ml} / \mathrm{m}^{2}\right)$} \\
\hline Crystalloid & $128 \pm 33$ & $113 \pm 28$ & $123 \pm 30$ \\
\hline HES $130 / 0.4$ & $143 \pm 39$ & $122 \pm 32$ & $138 \pm 49$ \\
\hline \multicolumn{4}{|l|}{$\mathrm{SvO}_{2}(\%)$} \\
\hline Crystalloid & $76 \pm 12$ & $66 \pm 9$ & $72 \pm 9^{*}$ \\
\hline HES $130 / 0.4$ & $80 \pm 6$ & $66 \pm 9$ & $73 \pm 6$ \\
\hline
\end{tabular}

Data given as mean \pm SD.

T1, after induction of anesthesia; T2, during graft of obtuse marginal branch; T3, during closure of sternum; HES, hydroxyethyl starch; MAP, mean arterial pressure; $\mathrm{Cl}$, cardiac index; CVP, central venous pressure; MPAP, mean pulmonary artery pressure; RVEDVI, right ventricular end diastolic volume index; $\mathrm{SvO}_{2}$, mixed venous oxygen saturation.

\begin{tabular}{|c|c|c|c|}
\hline & $\begin{array}{l}\text { Crystalloid } \\
(\mathrm{N}=53)\end{array}$ & $\begin{array}{c}\text { HES } 130 / 0.4 \\
(N=53)\end{array}$ & $P$ value \\
\hline \multicolumn{4}{|c|}{ Hemoglobin (g/dl) } \\
\hline Preoperative & $13.9 \pm 1.3$ & $13.5 \pm 1.5$ & 0.129 \\
\hline POD1* & $10.9 \pm 1.2$ & $10.0 \pm 1.3$ & $<0.001$ \\
\hline \multicolumn{4}{|l|}{ INR } \\
\hline Preoperative & $1.0 \pm 0.1$ & $1.0 \pm 0.1$ & 0.237 \\
\hline POD1* & $1.1 \pm 0.1$ & $1.1 \pm 0.1$ & 0.028 \\
\hline \multicolumn{4}{|l|}{ aPTT (s) } \\
\hline Preoperative & $36.1 \pm 13.0$ & $33.2 \pm 9.7$ & 0.194 \\
\hline POD1 & $33.7 \pm 9.8$ & $32.8 \pm 7.6$ & 0.583 \\
\hline \multicolumn{4}{|c|}{ Platelet count $\left(10^{3} / \mathrm{L}\right)$} \\
\hline Preoperative & $233 \pm 63$ & $252 \pm 62$ & 0.122 \\
\hline POD1 & $172 \pm 53$ & $174 \pm 48^{\dagger}$ & 0.808 \\
\hline
\end{tabular}

Data given as mean \pm SD.

${ }^{*} P<0.05$ crystalloid vs. HES $130 / 0.4$.

HES, hydroxyethyl starch; INR, international ratio of prothrombin time; aPTT, activated partial thromboplastin time; POD1, postoperative day 1 .

of infused norepinephrine and injected vasopressin was also similar between the groups. The frequency of vasopressin infusion for severe hypotension was also not different (4 and 5 in the crystalloid and HES 130/0.4 groups, respectively, P>0.999).

Acute renal failure developed in 1 and 0 patients in the HES $130 / 0.4$ and crystalloid groups, respectively $(\mathrm{P}=0.315)$, and the patient who developed renal failure in the HES 130/0.4 group
Table 5. Changes in Thromboelastography Variables

\begin{tabular}{lcccc} 
R (min) & T0 & T1 & T2 & $\begin{array}{c}\text { Reference } \\
\text { value }\end{array}$ \\
Crystalloid & $20.1 \pm 7.6$ & $22.6 \pm 15.6$ & $22.2 \pm 11.6$ & $12-27$ \\
HES 130/0.4 & $23.0 \pm 10.3$ & $28.4 \pm 19.8$ & $19.7 \pm 7.1$ & \\
P value & 0.156 & 0.163 & 0.329 & \\
K (min) & & & & \\
Crystalloid & $9.9 \pm 4.8$ & $13.7 \pm 10.4$ & $11.4 \pm 5.7$ & $3-13$ \\
HES 130/0.4 & $12.4 \pm 7.4$ & $17.1 \pm 10.7$ & $12.2 \pm 5.8$ & \\
P value & 0.074 & 0.169 & 0.575 & \\
MA & & & & \\
Crystalloid & $47.4 \pm 8.5$ & $43.6 \pm 10.4$ & $46.4 \pm 10.5$ & $42-63$ \\
HES 130/0.4 & $46.6 \pm 9.3$ & $40.0 \pm 10.8$ & $44.5 \pm 7.2$ & \\
P value & 0.711 & 0.147 & 0.430 & \\
$\alpha$-angle ( ${ }^{\circ}$ ) & & & & \\
Crystalloid & $24.4 \pm 9.3$ & $22.7 \pm 11.6$ & $24.3 \pm 14.6$ & $14-46$ \\
HES 130/0.4 & $22.5 \pm 11.1$ & $18.5 \pm 11.8$ & $21.9 \pm 12.7$ & \\
P value & 0.413 & 0.125 & 0.499 & \\
\hline
\end{tabular}

Data given as mean \pm SD.

T0, baseline before induction of anesthesia; T1, $15 \mathrm{~min}$ after sternum closure; T2, $5 \mathrm{~h}$ after arrival in the ICU; R, reaction time; HES, hydroxyethyl starch; $\mathrm{K}$, kinetic time; MA, maximum amplitude.

required hemodialysis. The length of stay in the ICU $(2.7 \pm 1.1$ days and $2.7 \pm 0.8$ days in the crystalloid and HES 130/0.4 groups, respectively, $\mathrm{P}=0.916)$ and in the hospital $(10.3 \pm 3.7$ days and 10.9 \pm 5.7 days in the crystalloid and HES 130/0.4 groups, respectively, $\mathrm{P}=0.484$ ) postoperatively, and the incidence of other adverse events postoperatively were not different between the groups.

\section{Discussion}

In the present prospective, randomized trial addressing the safety of a moderate dose of $6 \%$ HES 130/0.4 compared to crystalloid solution in patients undergoing OPCAB with recent exposure to DAPT, no differences were observed in terms of perioperative blood loss. Transfusion requirements and coagulation variables (including TEG parameters) were also not different, although the postoperative hemoglobin level was lower and the INR was higher in the HES 130/0.4 group.

The HES solutions have been reported to induce a type I von Willebrand-like syndrome with decreased factor VIII coagulant activity and decreased von Willebrand factor antigen and VIII-related ristocetin cofactor levels. ${ }^{26}$ These effects manifest as an increase in $\mathrm{r}$ (time-to-initial fibrin formation) and $\mathrm{k}$ (rapidity of fibrin cross-linking), and a decrease in MA (clot strength, and activities of fibrin and platelets) and $\alpha$-angle (speed of clot formation) on TEG that are associated with an actual increase in blood loss during cardiac surgery. ${ }^{27}$ Accounting for the important role of molecular weight and degree of substitution ratio on hemostasis, HES 130/0.4 was developed with a lower molecular weight and lower C2/C6 ratio, resulting in rapid total body clearance. Accordingly, HES 130/0.4 was found to retain the significant plasma volume expansion effect with a minimal influence on coagulation. Indeed, while HES 200/0.5 disturbed blood coagulation and increased bleeding at a maximum dose $(33 \mathrm{ml} / \mathrm{kg})$, HES 130/0.4 had less of an effect on blood coagulation and bleeding at loading doses up to $50 \mathrm{ml} / \mathrm{kg} \cdot{ }^{18,21} \mathrm{In}$ a study addressing the safety in cardiac surgery under CPB when used as a component of a priming 
solution, dose-dependent alterations in coagulation without an actual increase in blood loss were observed. ${ }^{28}$

With increased clinical application of DAPT (aspirin and clopidogrel), concerns for potential hemorrhagic complications arising from the use of these agents in proximity to coronary artery bypass grafts (CABG) have become an important issue. In these patients, OPCAB has been proposed as an alternative surgical revascularization technique because the major deteriorating effect on the coagulation system (CPB) is avoided. ${ }^{7-9}$ Indeed, OPCAB has been safely performed without an increased risk of transfusion requirement in patients with recent exposure to clopidogrel. ${ }^{25}$ Thus, an increased number of patients has continued antiplatelet agent therapy before OPCAB, notwithstanding the guideline recommending discontinuation of antiplatelet agents at least 5 days before surgery. ${ }^{4}$ Although the pharmacokinetic properties of HES 130/0.4 produced minimal disturbances in hemostasis, hemodilution per se causes lower platelet availability, which may pose the additional risk of increased bleeding in patients in need of continued antiplatelet therapy perioperatively. This assumption, however, has not been validated heretofore.

In the current study $6 \%$ HES $130 / 0.4$ solution at a maximum dose of $30 \mathrm{ml} \cdot \mathrm{kg}^{-1} \cdot$ day $^{-1}$ did not increase the amount of perioperative blood loss and transfusion requirements compared to a balanced crystalloid solution. Indeed, based on the coagulation profile, $6 \%$ HES 130/0.4 produced similar changes in aPTT and TEG parameters as a balanced crystalloid solution. Although the prothrombin time INR was higher in the HES 130/0.4 group than the crystalloid group, the difference was small and not likely to be clinically significant. Both groups demonstrated an increase in $\mathrm{r}$ and $\mathrm{k}$ time, and a decrease in $\alpha$-angle and MA indicative of hemodilution, which returned to baseline $5 \mathrm{~h}$ postoperatively. These changes are in agreement with the TEG findings following OPCAB when only normal saline was used, ${ }^{27}$ and may be attributable to the favorable pharmacokinetic property of rapid total body clearance, considering that most of the HES 130/0.4 was given intraoperatively. The present results clearly demonstrate the safety of an infusion of HES 130/0/4 with regard to perioperative bleeding and coagulation when used at $30 \mathrm{ml} \cdot \mathrm{kg}^{-1}$. day ${ }^{-1}$, even in patients with recent exposure to DAPT.

Although the present study was not designed to address the following, we did not observe any differences in the postoperative outcome variables, including postoperative $\mathrm{Cr}$ levels and the incidence of acute renal failure between the groups. Concerns have been raised previously regarding the negative influence of HES on possible renal impairment. ${ }^{29-31}$ Limited use of HES $130 / 0.4$ at $30 \mathrm{ml} \cdot \mathrm{kg}^{-1} \cdot \mathrm{day}^{-1}$, however, as in the current study, does not appear to influence renal function.

The limitations of the present study were as follows. We did not measure occult intraoperative blood loss by comparing the weights of soaked tapes and gauzes to the dry counterparts, which may have confounded the result regarding the hemoglobin level. The observed difference in the postoperative hemoglobin level, however, may more likely be attributable to the following reason. Unexpectedly, the total amount of infused volume to achieve the pre-defined hemodynamic goals was not significantly greater in the crystalloid group. The only finding reflecting the more efficient volume expansion capability of HES was the significantly lower postoperative hemoglobin levels in the HES 130/0.4 group despite a similar amount of blood loss and transfusion requirements, which is in agreement with previous studies. ${ }^{28,32} \mathrm{~A}$ recent goal-directed resuscitation study involving critically ill patients found that a volume ratio of crystalloid-to-HES achieved an equivalent plasma volume in the range of only $1: 1.6 .^{33,34}$ Therefore, based on the amount of total infused volume and vasopressors we cannot conclude whether or not HES 130/0.4 was superior in terms of expanding plasma volume and improving microperfusion, which had already been confirmed in a number of previous studies. ${ }^{11-16}$ Second, the SD of perioperative blood loss in the current study was $370 \mathrm{ml}$, whereas the present sample size calculation was based on an SD of $250 \mathrm{ml}$. Therefore, the present study may have been underpowered to detect 150 -ml difference in perioperative blood loss between the groups. Third, although the discontinuation date of the antiplatelet agents was similar between the groups, substantial interindividual variability exists in platelet response to clopidogrel. ${ }^{35,36}$ There is currently no generally accepted platelet function assay, however, that has been demonstrated to correlate well with post-surgical blood loss. Therefore, the influence of individual platelet responsiveness to clopidogrel on the present trial remains inconclusive.

In conclusion, 6\% HES 130/0.4 $\left(\leq 30 \mathrm{ml} \cdot \mathrm{kg}^{-1} \cdot \mathrm{day}^{-1}\right)$ was not associated with an increased amount of perioperative blood loss or transfusion requirements compared to crystalloid solutions in patients with recent exposure to DAPT undergoing OPCAB. HES 130/0.4 also caused a similar degree and duration of coagulation impairment to that observed when only crystalloid solution was given during OPCAB.

\section{References}

1. Mehta SR, Yusuf S. The Clopidogrel in Unstable angina to prevent Recurrent Events (CURE) trial programme; rationale, design and baseline characteristics including a meta-analysis of the effects of thienopyridines in vascular disease. Eur Heart J 2000; 21: 2033 2041

2. Fox KA, Mehta SR, Peters R, Zhao F, Lakkis N, Gersh BJ, et al. Benefits and risks of the combination of clopidogrel and aspirin in patients undergoing surgical revascularization for non-ST-elevation acute coronary syndrome: The Clopidogrel in Unstable angina to prevent Recurrent ischemic Events (CURE) Trial. Circulation 2004; 110: $1202-1208$.

3. Peters RJ, Mehta SR, Fox KA, Zhao F, Lewis BS, Kopecky SL, et al. Effects of aspirin dose when used alone or in combination with clopidogrel in patients with acute coronary syndromes: Observations from the Clopidogrel in Unstable angina to prevent Recurrent Events (CURE) study. Circulation 2003; 108: 1682-1687.

4. Dunning J, Versteegh M, Fabbri A, Pavie A, Kolh P, Lockowandt U, et al. Guideline on antiplatelet and anticoagulation management in cardiac surgery. Eur J Cardiothorac Surg 2008; 34: 73-92.

5. Chu MW, Wilson SR, Novick RJ, Stitt LW, Quantz MA. Does clopidogrel increase blood loss following coronary artery bypass surgery? Ann Thorac Surg 2004; 78: 1536-1541.

6. Kapetanakis EI, Medlam DA, Petro KR, Haile E, Hill PC, Dullum $\mathrm{MK}$, et al. Effect of clopidogrel premedication in off-pump cardiac surgery: Are we forfeiting the benefits of reduced hemorrhagic sequelae? Circulation 2006; 113: 1667-1674.

7. Ishida M, Kobayashi J, Tagusari O, Bando K, Niwaya K, Nakajima $\mathrm{H}$, et al. Perioperative advantages of off-pump coronary artery bypass grafting. Circ J 2002; 66: 795-799.

8. Chassot PG, van der Linden P, Zaugg M, Mueller XM, Spahn DR. Off-pump coronary artery bypass surgery: Physiology and anaesthetic management. Br J Anaesth 2004; 92: 400-413.

9. Rastan AJ, Eckenstein JI, Hentschel B, Funkat AK, Gummert JF, Doll N, et al. Emergency coronary artery bypass graft surgery for acute coronary syndrome: Beating heart versus conventional cardioplegic cardiac arrest strategies. Circulation 2006; 114: I477-I485.

10. Song SW, Youn YN, Yi G, Lee S, Yoo KJ. Effects of continuous administration of clopidogrel before off-pump coronary artery bypass grafting in patients with acute coronary syndrome. Circ J 2008; 72: 626-632.

11. Gallandat Huet RC, Siemons AW, Baus D, van Rooyen-Butijn WT, Haagenaars JA, van Oeveren W, et al. A novel hydroxyethyl starch (Voluven) for effective perioperative plasma volume substitution in cardiac surgery. Can J Anaesth 2000; 47: 1207-1215.

12. Haljamae H. Volume substitution in shock. Acta Anaesthesiol Scand Suppl 1993; 98: 25-28. 
13. Funk W, Baldinger V. Microcirculatory perfusion during volume therapy: A comparative study using crystalloid or colloid in awake animals. Anesthesiology 1995; 82: 975-982.

14. Wang P, Hauptman JG, Chaudry IH. Hemorrhage produces depression in microvascular blood flow which persists despite fluid resuscitation. Circ Shock 1990; 32: 307-318.

15. Kjellgren P, Gupta A, Sjoberg F. Volume replacement during cardiac surgery-influence on microcirculation. Acta Anaesthesiol Scand 1995; 39: $709-710$.

16. Standl T, Burmeister MA, Schroeder F, Currlin E, Schulte am Esch J, Freitag M. Hydroxyethyl starch (HES) 130/0.4 provides larger and faster increases in tissue oxygen tension in comparison with prehemodilution values than HES 70/0.5 or HES 200/0.5 in volunteers undergoing acute normovolemic hemodilution. Anesth Analg 2003; 96: 936-943.

17. Entholzner EK, Mielke LL, Calatzis AN, Feyh J, Hipp R, Hargasser SR. Coagulation effects of a recently developed hydroxyethyl starch (HES 130/0.4) compared to hydroxyethyl starches with higher molecular weight. Acta Anaesthesiol Scand 2000; 44: 1116-1121.

18. Kasper SM, Meinert P, Kampe S, Gorg C, Geisen C, Mehlhorn U, et al. Large-dose hydroxyethyl starch 130/0.4 does not increase blood loss and transfusion requirements in coronary artery bypass surgery compared with hydroxyethyl starch 200/0.5 at recommended doses. Anesthesiology 2003; 99: 42-47.

19. Cabrales P, Tsai AG, Intaglietta M. Resuscitation from hemorrhagic shock with hydroxyethyl starch and coagulation changes. Shock 2007; 28: $461-467$.

20. Shroyer AL, Coombs LP, Peterson ED, Eiken MC, DeLong ER, Chen A, et al. The Society of Thoracic Surgeons: 30-day operative mortality and morbidity risk models. Ann Thorac Surg 2003; 75: 1856-1865.

21. Van der Linden PJ, De Hert SG, Deraedt D, Cromheecke S, De Decker K, De Paep R, et al. Hydroxyethyl starch 130/0.4 versus modified fluid gelatin for volume expansion in cardiac surgery patients: The effects on perioperative bleeding and transfusion needs. Anesth Analg 2005; 101: 629-634.

22. Bellomo R, Ronco C, Kellum JA, Mehta RL, Palevsky P. Acute renal failure-definition, outcome measures, animal models, fluid therapy and information technology needs: The Second International Consensus Conference of the Acute Dialysis Quality Initiative (ADQI) Group. Crit Care 2004; 8: R204-R212.

23. Nesher N, Alghamdi AA, Singh SK, Sever JY, Christakis GT, Goldman BS, et al. Troponin after cardiac surgery: A predictor or a phenomenon? Ann Thorac Surg 2008; 85: 1348 - 1354.

24. Hecht-Dolnik M, Barkan H, Taharka A, Loftus J. Hetastarch increases the risk of bleeding complications in patients after off-pump coronary bypass surgery: A randomized clinical trial. $J$ Thorac Cardiovasc Surg 2009; 138: 703-711.

25. Shim JK, Choi YS, Oh YJ, Bang SO, Yoo KJ, Kwak YL. Effects of preoperative aspirin and clopidogrel therapy on perioperative blood loss and blood transfusion requirements in patients undergoing offpump coronary artery bypass graft surgery. J Thorac Cardiovasc Surg 2007; 134: 59-64.

26. Hillman K, Bishop G, Bristow P. The crystalloid versus colloid controversy: Present status. Baillière Clin Anaesthesiol 1997; 11: 1-13.

27. Yen TS, Chan KC, Cheng YJ. Intraoperative coagulation was more interfered by HES 200/0.5 than normal saline in off-pump coronary artery bypass surgery. J Cardiovasc Surg (Torino) 2008; 49: 679684.

28. Schramko A, Suojaranta-Ylinen R, Kuitunen A, Raivio P, Kukkonen $\mathrm{S}$, Niemi T. Hydroxyethylstarch and gelatin solutions impair blood coagulation after cardiac surgery: A prospective randomized trial. Br J Anaesth 2010; 104: 691-697.

29. Cittanova ML, Mavre J, Riou B, Coriat P. Long-term follow-up of transplanted kidneys according to plasma volume expander of kidney donors. Intensive Care Med 2001; 27: 1830.

30. Winkelmayer WC, Glynn RJ, Levin R, Avorn J. Hydroxyethyl starch and change in renal function in patients undergoing coronary artery bypass graft surgery. Kidney Int 2003; 64: 1046-1049.

31. Hartog C, Reinhart K. CONTRA: Hydroxyethyl starch solutions are unsafe in critically ill patients. Intensive Care Med 2009; 35: 1337 1342.

32. Nielsen VG. Hemodilution modulates the time of onset and rate of fibrinolysis in human and rabbit plasma. J Heart Lung Transplant 2006; 25: 1344-1352.

33. Verheij J, van Lingen A, Raijmakers PG, Rijnsburger ER, Veerman DP, Wisselink W, et al. Effect of fluid loading with saline or colloids on pulmonary permeability, oedema and lung injury score after cardiac and major vascular surgery. Br J Anaesth 2006; 96: 21 -30.

34. Brunkhorst FM, Engel C, Bloos F, Meier-Hellmann A, Ragaller M, Weiler $\mathrm{N}$, et al. Intensive insulin therapy and pentastarch resuscitation in severe sepsis. $N$ Engl J Med 2008; 358: 125-139.

35. Ikeda T, Taniguchi R, Watanabe S, Kawato M, Kondo H, Shirakawa $\mathrm{R}$, et al. Characterization of the antiplatelet effect of aspirin at enrollment and after 2-year follow-up in a real clinical setting in Japan. Circ J 2010; 74: 1227-1235.

36. Jinnai T, Horiuchi H, Makiyama T, Tazaki J, Tada T, Akao M, et al. Impact of CYP2C19 polymorphisms on the antiplatelet effect of clopidogrel in an actual clinical setting in Japan. Circ J 2009; 73: 1498 1503 . 